\title{
Ethical aspects of genetic disease and genetic counselling
}

\author{
Richard West St George's Hospital Medical School, London
}

\section{Author's abstract}

With the reduction in diseases due to nutritional deficiencies and infection, disorders which are wholly or partly genetic are becoming relatively more important in all branches of modern medicine.

Genetic counselling has developed in recent years from just explaining to an individual or a couple the risk of them producing a handicapped child, to the possibility in many cases of better diagnosis and active intervention to reduce the risks. At the same time antenatal screening programmes have been introduced to detect women who may be carrying a fetus with a severe handicapping anomaly.

The ethical aspects of these advances are considered in this article. A practical approach to the resolution of any dilemmas is proposed which concentrates on the duties incumbent on doctors and other health care workers involved with patients who have or may carry genetic disorders.

\section{Introduction}

Genetic disorders are common and are seen in all medical specialties. Most are first manifest in childhood, and in developed countries the decline in importance of infective disease and nutritional deficiencies in childhood has led to congenital and genetic disorders becoming relatively more important. It is estimated that wholly or partly inherited disorders now account for between 11 and 27 per cent of hospital admissions of children, and are a major factor in 50 per cent of childhood deaths (1).

In recent years there have been technological advances and growth in understanding of inheritance so that new practical applications have been and are being introduced into patient care in the management of genetic disease.

As genetic medicine and counselling can cover such topics as whether a couple should reproduce, the possibility of handicap in the offspring, and the investigation and possible termination of pregnancy they raise many ethical issues $(2,3)$. The World Medical Association issued a brief statement of guidance on genetic counselling and genetic

\section{Key words}

Genetic counselling. engineering in 1987 that highlights some of the issues they see as crucial (4), and the King's Fund has recently held a consensus conference on screening for fetal and genetic abnormality which highlighted some of the ethical issues (5). Genetic engineering is outside the scope of this article.

\section{Doctor-patient relationships in genetic disease}

There are three different types of doctor-patient relationship in genetic disease, each of which imposes different duties on the doctor.

Firstly, doctors in any specialty may care for patients whose disease is largely or wholly genetic. As with other patients the doctor's primary responsibility will be the diagnosis and management of the patient's medical condition. The doctor should explain to the patient the genetic aspects of the condition, and must point out if there are implications for other family members. Referral of the patient or relatives to a geneticist is appropriate where the doctor does not have the necessary knowledge or skills for giving genetic advice.

Secondly, doctors may be specifically involved in evaluating, from a genetic point of view, prospective parents before conception. This applies to individuals or couples who seek advice because they have had a child with an abnormality that may be genetic, or because such a disorder is in the family, or affects the individual seeking help. Couples who are consanguineous may also seek advice. When the doctor is involved in investigating a family in which there is a genetic problem he or she may have to take the initiative in seeking out family members who could be carriers of a genetic problem.

Thirdly, with the development of screening procedures for congenital and genetic disorders either before or during pregnancy doctors are involved in ensuring that there is informed consent to the procedure, and in meeting the need for skilled counselling if an abnormal condition is found.

\section{Stages in genetic counselling}

The aim of genetic counselling is to inform the patient or patients of the risks of genetic disease occuring in their offspring or those of other family members, and to advise them of the options for reducing that risk. 
This should have the effect of reducing the number of individuals being born with severe handicapping conditions of genetic origin.

Genetic diagnosis has to precede counselling, and consists of ascertaining both a full family history and as precise a diagnosis as possible of any congenital or genetic disease. An accurate diagnosis is important, as in some situations a given phenotype may have more than one genetic cause, or even not be genetic at all.

Counselling consists of a) giving information to an individual or a couple on the likelihood of them producing a child with a disease or abnormality, b) advising them on the implications of producing such a child, including providing medical information about the severity and treatment of the condition, $c$ ) advising them of the ways the risk might be reduced, and d) helping them to understand and come to terms with this information, so that they can make informed decisions about whether to embark on a pregnancy.

\section{Reducing the risk of having a baby with a handicapping condition}

The desire to have children of one's own can be very strong, and many couples will decide to have children even when they know the risk is high and the disease serious. The options available for lowering the risks of producing a child with a disability will depend both on the form of inheritance, and on the disease itself. The major options which are technically feasible are listed beow. Many of them raise moral dilemmas for some couples and also for some doctors.

1) Discriminatory pairing In families where there is a serious recessive disorder the doctor should point out the risks inherent in cousin marriage. If it is possible to test for the carrier state it can be determined whether there is a risk for a particular pairing.

Screening adolescents to detect heterozygotes of serious recessive disorders has been practised for conditions such as Tay-Sachs disease, thalassaemia and sickle cell disease. Heterozygous individuals are counselled and advised to have prospective partners tested for carrier status before embarking on joint parenthood.

2) Not having children Many couples who have had a child with a handicapping condition which could recur will opt not to have further children. Similarly some couples found to be carriers of genetic disease, either because of screening or a family study may make this decision.

3) Changing partners Marital breakdown sometimes occurs when a couple have produced a child with a handicapping condition. Genetically, for recessive disorders it may enable both partners to have other children without risk of recurrence. For an individual with a dominant disease, or carrying an $\mathrm{x}$-linked condition or a balanced translocation the risk will remain high with any partner.

4) Minimising the risk by selective abortion With the use of chorionic villous biopsy, amniocentesis, fetoscopy, fetal blood sampling or ultrasound screening it is possible to detect many genetic disorders or serious abnormalities of the fetus in early $\stackrel{\unrhd}{\stackrel{2}{2}}$ pregnancy. If an abnormality is found to be present the $\overrightarrow{ \pm}$. woman could then be offered an abortion. For many $\bar{\complement}$ $\mathrm{x}$-linked disorders it is possible to determine by specific testing that a fetus is likely to be affected. $\stackrel{\overrightarrow{0}}{\stackrel{9}{+}}$ Where this is not possible the abortion of all male? fetuses prevents the birth of affected individuals, but not of carrier females.

Women not thought to be at particular risk may be $\frac{\mathbb{Q}}{\Omega}$ found by ultrasound screening in early pregnancy to be carrying a fetus with a major abnormality such as? anencephaly or spina bifida. Amniocentesis screening of older women for Down's Syndrome will also identify $\vec{\omega}$ affected fetuses where the mothers were not at $\stackrel{\circ}{?}$ particular risk, apart from their age. Decisions on whether to consider abortion have then to be made quickly.

5) Artificial insemination Where a couple are both $\stackrel{+}{+}$ known to be carriers of a harmful recessive gene the use $\vec{\rho}$ of artificial insemination from an unrelated donor cano result in a pregnancy with minimal risk of handicap.

6) Ovum transfer Where a woman carries an $\mathrm{x}$-linked harmful gene, ovum transfer (gamete intrafallopian transfer, GIFT) would be one way she could have a low-risk pregnancy.

7) Treatment of the fetus in utero It seems probable ${ }^{\mathbb{\Phi}}$ that the incidence of spina bifida is lowered in high-risk $\overrightarrow{0}$ families where mothers take vitamin and mineflo supplements before conception (6). In some conditio so damage to a fetus can be prevented by medien treatment given to the mother. Dietary control of $\overrightarrow{0}$ blood phenylalanine in mothers with phenylketonuriag prevents mental handicap in the baby; steroids can $\mathbb{Q}$ prevent virilisation of the fetus in congenital adrenal hyperplasia. Surgical treatment of the fetus may also be윽 possible. Fetal bladder catheterisation in urinary obstruction has been successful in preventing rena官 damage, and further developments of this approach are likely.

8) Genetic manipulation of the fetus In the future it may be possible to implant into a fetus a missing gene to prevent the development of a disease. Attempts haveo already been made at marrow and organ trans $\frac{\overline{3}}{3}$ plantation in some recessive conditions (7). The use ofo specific gene clones may one day become possible.

\section{Areas of ethical uncertainty in genetic counselling}

Many of the steps listed above that necessitate activen intervention and can be taken to alter the risk of producing a baby with a handicap are well recognised areas of moral uncertainty. Consensus does not exisk over abortion, fetal rights, artificial insemination ${ }^{\circ}$ ovum transfer or genetic manipulation. The arguments? will not be restated here.

There is, however, general agreement that the doctor should respect the conscience and moral beliefsD of the patient, and not impose his personal mora $\frac{P}{D}$ values. A doctor may choose not to give genetic advice where it conflicts with his own conscience, but in thak situation he should alert the parents where there is a 
potential genetic problem, and advise them to seek genetic counselling.

Less well established are the issues of who should be given genetic advice, confidentiality and family information, which handicaps are severe enough to warrant intervention, and the particular problems of screening.

WHO SHOULD BE GIVEN GENETIC ADVICE AND WHO OWNS FAMILY INFORMATION?

A patient with a genetic disease and those seeking genetic advice should be given appropriate information and counselling. Indeed failure to do so, or giving wrong advice could be grounds for an action for negligence. Information given which is reinforced by writing to the patient goes some way to ensuring that the advice given is both understood and remembered.

Making a genetic diagnosis may have implications for some members of the extended family. For instance the sisters of a woman whose child has an $\mathrm{x}$-linked disorder may also be carriers; a patient with a dominant disorder like Huntingdon's chorea may have first and second degree relatives who also carry the gene, and may pass it on, and in a family where consanguinity is common a recessive disorder may recur in other sibships. The doctor has a duty to other family members even if he has a special relationship with one family member.

The doctor also has a duty to the family to collect as much diagnostic information as possible. It may seem hard at a time when a family are distressed over a stillbirth or child death to recommend a post mortem, but it may be vital in establishing a precise diagnosis. Similarly the opportunity should not be lost to take photographs, x-rays, or blood and fibroblast specimens.

Not imparting relevant information that an individual might reasonably be expected to be told is difficult to justify. Sometimes imparting information could be thought as being potentially harmful, perhaps because of its effect on the mental state of a carrier of a harmful gene (particularly one with delayed effect like Huntingdon's chorea), or because it might disrupt a marriage. In most cases such paternalistic arguments are outweighed by the potential harm that could arise through not knowing.

A further difficulty in advising relevant members of the extended family may be the question of confidentiality. In most cases the family will readily share information amongst its members, and the relatives can then seek advice for themselves. When the index clients are reluctant to communicate with other family members every effort should be made by the doctor to persuade them. Where this approach fails the doctor must decide whether the need to know that one may be the carrier of a potentially harmful gene outweighs the duty of confidentiality to the index patient.

This will depend both on the severity of the condition and the likelihood of the person having affected offspring. For severe sex-linked disorders such as Duchenne muscular dystrophy or fragile-x syndrome the need of the sister of a carrier mother to know that she may also be a carrier outweighs the duty to preserve absolute confidentiality. If confidentiality is to be breached in this limited way the index patient should be informed, and the reasons explained.

As a general principle all members of a family should have a right of access to information about genetic disease within the family which might be of importance to them.

\section{THE SEVERITY OF HANDICAP}

One of the primary aims of genetic counselling is to reduce the numbers of babies born with serious handicap. In Britain conscientious objection to abortion on the grounds of fetal abnormality is only the viewpoint of a minority. However, difficulties can arise over a patient's perception of the severity of a handicap.

Few would disagree with a decision to terminate an early pregnancy where the fetus was shown to have anencephaly, or to have spina bifida, which it is known results in a poor quality of life for the child and serious problems for the family. For Down's Syndrome, where although the child is going to be mentally handicapped the quality of life for the individual can be very good, there might be less certainty. Termination of a fetus that has a surgically correctable abnormality cannot be rationally justified, although for some parents the detection of any abnormality may provoke a request for abortion.

PARTICULAR PROBLEMS OF ANTENATAL SCREENING

Apart from testing the fetus where there is known to be a familial risk of a handicapping condition, there are some screening procedures that are more widely used. Before undergoing these procedures women should be informed of the possibility of detection of fetal abnormality.

Ultrasound screening of the fetus is offered to all women in pregnancy to assess fetal maturity. At the same time the fetus is examined morphologically, and a severe fetal abnormality such as anencephaly or spina bifida may be detected. Screening for Down's Syndrome in older mothers by chromosomal analysis of fetal tissue obtained by amniocentesis or chorionic villous biopsy is offered in many centres.

Where an abnormality is discovered by antenatal screening the mother has to be informed and rapidly counselled about the implications of the discovery. A decision either to continue with the pregnancy or to have a termination has to be taken rapidly. The mother must be given enough information, support and counselling to enable her to make an autonomous decision, and she must decide on how much her partner should be involved in the decision-making.

An additional problem sometimes arises in chromosomal screening for Down's Syndrome, in that other chromosomal anomalies may be detected instead. Where these are known to be associated with severe handicap the woman can be appropriately counselled. More difficult are the chromosomal 
anomalies associated with less severe handicap or inconstantly associated with disease, such as Turner's syndrome, XXX and XYY. The doctor has a duty to inform the parents about the results of the test, but may not be in a position to say whether the baby is going to be seriously handicapped by the chromosomal anomaly. Included in the information given to a mother before screening for Down's Syndrome should be the possibility of the test detecting other anomalies and that if this happens she will be appropriately counselled about the possible significance of the anomaly.

\section{Duties of doctors when dealing with genetic disease}

Many of the practical and ethical problems concerning genetic counselling and the management of genetic diseases are made easier for the doctor (or other health worker) by summarising the medical responsibilites. Inevitably some items included on such a list are debatable, but it is suggested that the following should be generally acceptable. They are in harmony with, and some are based on, the World Medical Association Statement on Genetic Counselling and Genetic Engineering (4).

\section{OBLIGATIONS AFFECTING ALL DOCTORS}

Doctors have a duty to inform patients when they know of genetic factors that could lead to significant genetic or congenital disease in the offspring of the patient or other family members. The doctor should either give genetic advice himself, or offer referral to a geneticist for such advice.

The patient should be encouraged where appropriate to disseminate relevant genetic information within the family. The physician must be prepared to see other family members personally or refer them to an appropriate physician.

Doctors whose own moral values are opposed to abortion, sterilisation or contraception may choose not to give genetic advice. They must, however, inform prospective parents where a potential genetic problem exists, and advise that they seek the opinion of a clinical geneticist, and arrange such a referral.

Doctors should be aware that genetic dignosis and screening is a field of rapid advance; the doctor has a duty to provide up-to-date information, or to refer to someone who can provide it.

When a genetic defect is found in a fetus prospective parents may or may not want an abortion. Doctors should avoid the substitution of their own moral judgement in place of that of the prospective parents.

A doctor should not breach his patient's confidentiality over genetic matters unless he has discussed the need to do so with the patient. If, in spite

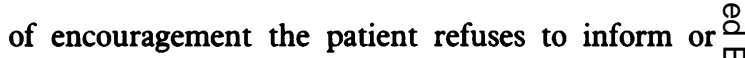
involve other family members the doctor is entitled to $\frac{W}{\mp}$ limited breach of confidentiality to a third party where it is in the medical interest of that third party to know genetic information.

SPECIAL OBLIGATIONS OF MEDICAL GENETICISTS Doctors engaged in genetic counselling must provide $\frac{\bar{\sigma}}{\bar{\omega}}$ prospective parents with the basis for an informed decision for child-bearing.

\section{OBLIGATIONS CONCERNING GENETIC SCREENING}

Doctors should ensure that a woman is not to be $a \stackrel{\circ}{\circ}$ participant in a screening programme for genetic $\vec{\omega}$ disease or congenital abnormality without her $\stackrel{?}{?}$ informed consent. A woman's access to a screening or $\bar{\S}$ diagnostic test should be independent of any decision she may make about the continuation of the pregnancy.

A woman's considered and informed decision not to participate in a screening programming must be을 respected. Appropriate care and support must be $\rightarrow$ offered to her and the family.

\section{Acknowledgement}

I would like to acknowledge helpful criticism from응 Dr M Patton.

Richard West MD FRCP DCH has been Senior Lecture्षि, $\infty$ Department of Child Health, St George's Hospitul Medical School since 1975. He was Consultant to Genetic Counselling Clinic, St George's Hospital, 1979 1985, and Dean, St George's Hospital Medical School, 1982-1987.

\section{References}

(1) Emery A E H, Rimoin D L. Nature and incidence of genetic disease. In: Emery A E H, Rimoin D L, eds. Principles and practice of medical genetics. Edinburgh: Churchill Livingstone, 1983: 1-3.

(2) Arnold A, Moseley R. Ethical issues arising from medical: genetics. Fournal of medical ethics 1976; 2:12-17.

(3) Seller M J. Ethical aspects of genetic counselling. Fournal of medical ethics 1982; 8:185-188.

(4) World Medical Association. Statement on genetic counselling and genetic engineering. IME Bulletin 1987;윽 31:8-9.

(5) King's Fund forum consensus statement. Screening for을 fetal and genetic abnormality. British medical journal, 1987; 295:1551-1553.

(6) Smithells R W, Sheppard S, Schorah C J, et al. Possible N prevention of neural-tube defects by periconceptual vitamin supplementation. Lancet 1980; 1:339-340.

(7) Hobbs J R. Thirty-eight different metabolic errors (previously fatal) have been corrected by displacemento bone marrow transplantation. Archives of disease in childhood 1985; 60: 1097 (abstract). 